\title{
Investigation of vibration transmissibility for paper honeycomb sandwich structures with various moisture contents
}

\author{
Dong-Mei Wang ${ }^{1, *}$ and Rui Yang ${ }^{1,2}$ \\ ${ }^{1}$ School of Communication, Shenzhen Polytechnic, Shenzhen, PR China \\ ${ }^{2}$ Faculty of Printing, Packaging Engineering and Digital Media Technology, Xi'an University of Technology, Xi'an, PR China
}

Received: 28 August 2018 / Accepted: 9 January 2019

\begin{abstract}
Vibration transmissibility is an important factor to characterize the vibration absorption performance of cushioning packaging materials during transportation. Reasonable prediction of vibration transmissibility can guide antivibration design and reduce packaging cost. As a kind of green cushioning material, paper honeycomb sandwich structure is widely used in transport packaging because of its good machinability. But at the same time, it also has strong water absorption capacity. To a great extent, the vibration transmissibility of paper honeycomb sandwich structure may be affected by ambient humidity. In this research, the vibration transmissibility of paper honeycomb sandwich structures with various structure sizes under different humidity was tested by sine frequency sweep experiments. The rule of maximal vibration transmissibility with moisture content, cell length of honeycomb, and thickness of sandwich structure was analyzed. The results show that the maximal vibration transmissibility of paper honeycomb sandwich structure increases with the increase of moisture content, cell length of honeycomb, and thickness of sandwich structure. In order to construct the relationship between maximal vibration transmissibility and various factors, the moisture content was standardized. Finally, the maximal vibration transmissibility evaluation equation of paper honeycomb sandwich structure containing standardized moisture content and size of sandwich structure was obtained, which is of some reference value for vibration prediction of paper honeycomb sandwich structures.
\end{abstract}

Keywords: Paper honeycomb sandwich structure / moisture content / size of honeycomb structure / maximal vibration transmissibility

\section{Introduction}

In transportation, the packaging system is subjected to the continuous vibration from roads and vehicles, in which cushion materials play a key role in vibration reduction and absorption. The vibration transmissibility of cushion materials directly affects their vibration energy absorption capacity, and the cushioning materials with small vibration transmissibility can absorb more vibration energy. Paper honeycomb sandwich structure is often used as a cushion pad and cushioning packing box for transport packaging of electronic instruments, furniture, and so on. Ambient humidity and the size of sandwich structure may affect the vibration transmissibility of paper honeycomb sandwich structure, especially the ambient humidity, which affects the moisture content of paper and then seriously affects the mechanical properties of paper honeycomb sandwich structures.

\footnotetext{
* e-mail: 394794521@qq. com
}

Scholars in the 1960s and 1970s found that the elastic modulus and tensile strength of paper decrease with the increase of relative humidity, but the strain rate is the opposite [1-3]. As the moisture content of paper increases, the paper fiber absorbs moisture and swells, the free volume of paper fiber increases, and the hydrogen bond becomes more active, which leads to change in elastic modulus [1] and tensile strength [2] along with the phenomena of creep, time-dependent effect [4], and stress relaxation [5]. The Swedish scholar Kubát [6] analyzed the effect of humidity on the dynamic mechanical property of paper. He pointed out that the sudden change of humidity could cause the mechanical damping of paper to increase instantaneously, then reduce and stabilize, and he also said that the transient damping effect was related to the water diffusion process before paper reaches the water balance.

After a large number of paper materials applied for protective packaging in transportation, some scholars have also discussed the influence of changes in environmental temperature and humidity on the static and dynamic mechanical properties of paper cushioning packaging 


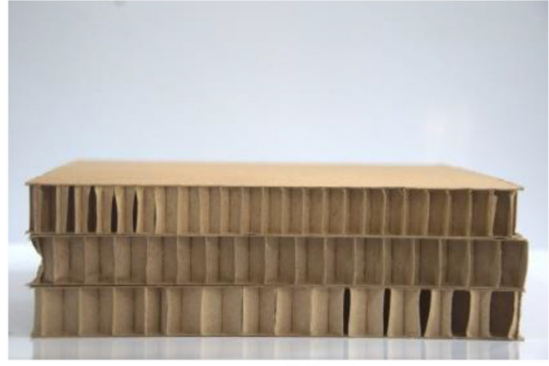

(a)

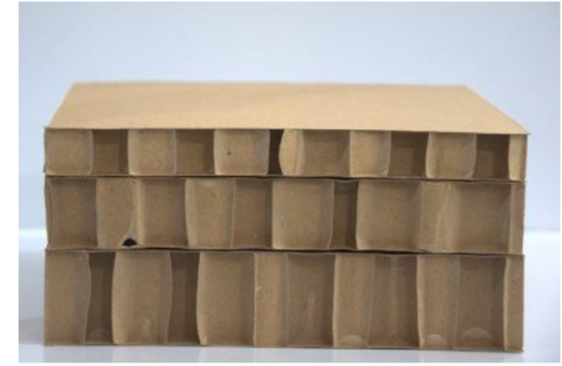

(b)

Fig. 1. Paper honeycomb sandwich structures: (a) cell length of honeycomb: 6, 8, and $10 \mathrm{~mm}$; (b) thickness of sandwich structure: 20, 30 , and $40 \mathrm{~mm}$.

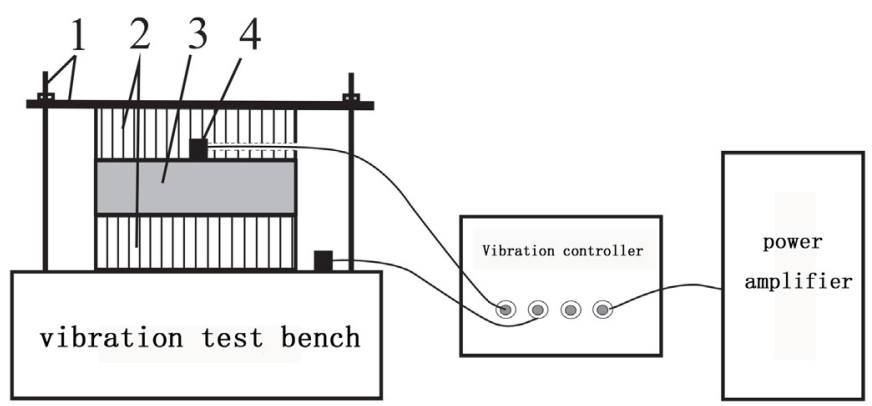

Fig. 2. Vibration test system: (1) fixture, (2) paper honeycomb sandwich structures, (3) mass block, and (4) acceleration sensor.

materials. Considering the effect of moisture content in transportation, the static and dynamic compressive stressstrain characteristics and energy absorption properties of paper honeycomb and paper corrugated sandwich structures systematically studied by Wang et al. [7-10], which are very helpful for the practical application of paper honeycomb and paper corrugated sandwich structures. Xiao and Shao [11] analyzed the static compression characteristics of molded pulp products with different temperature and humidity. In the surface compression test of paper corrugated sandwich structures with different humidity, Navaranjan et al. [12] discovered that the local flexion failure is easy to appear when the ambient humidity is large, and they further introduced that the mechanical properties of paper corrugated sandwich structures decreased because of the lignin in paper fibers that softened with the increase of moisture content. Vibration during transportation is similar to the action of multiple and small amplitude compression force, so the vibration transmissibility of paper honeycomb sandwich structure should also be affected by moisture content. Park et al. [13] described the influence of corrugated type, corrugated layer number, static stress, and ambient humidity on the vibration transmissibility of paper corrugated sandwich structures, which has certain reference value for paper honeycomb sandwich structures. Guo et al. [14-16] studied the effect of thickness and excitation frequency on vibration transmissibility of paper honeycomb sandwich structures. Zhang [17] also tested the vibration transmissibility of two layers of stacked honeycomb paper pallets. At present, to the author's knowledge, there is no relevant research between moisture content and vibration transmissibility of paper honeycomb sandwich structures.

The present study is dedicated to the vibration properties of different sizes of paper honeycomb sandwich structures under various moisture contents and attempts to explore the relationship of vibration transmissibility and several parameters, that is, moisture content, cell length of honeycomb, and thickness of sandwich structure. The paper focuses on establishing a universal equation for evaluating the maximal vibration transmissibility of paper honeycomb sandwich structures, which could help predict its vibration transmissibility without a lot of experiments.

\section{Experimental samples and method}

Experimental samples are the paper honeycomb sandwich structures with various thicknesses and various cell lengths of honeycomb, as given in Figure 1, which surface size is $200 \mathrm{~mm} \times 200 \mathrm{~mm}$. Samples with a core paper grammage of $110 \mathrm{~g} / \mathrm{m}^{2}$ are the main study object; those with a core paper grammage of $140 \mathrm{~g} / \mathrm{m}^{2}$ are the verification samples.

Before doing the experiment, all the samples are pretreated for $24 \mathrm{~h}$ at five different conditions, that is, $m_{1}$ $\left(23{ }^{\circ} \mathrm{C}, \mathrm{RH} 50 \%\right), m_{2}\left(23{ }^{\circ} \mathrm{C}, \mathrm{RH} 60 \%\right), m_{3}\left(23^{\circ} \mathrm{C}, \mathrm{RH} 70 \%\right)$, $m_{4}\left(23^{\circ} \mathrm{C}, \mathrm{RH} 80 \%\right)$, and $m_{5}\left(23^{\circ} \mathrm{C}, \mathrm{RH} 90 \%\right)$. Then with reference to ASTM D3580-95(2015) "Standard Test Methods for Vibration (Vertical Linear Motion) Test of Products," the sine frequency sweep experiment is carried out on the vibration test system (DC-300-3/SV-0404; Suzhou test group Limited by Share Ltd). The schematic diagram of the test system is shown in Figure 2. The vibration table simulates the vertical excitation of the base of a transport vehicle. The mass block is placed on the vibration table together with the paper honeycomb sandwich structures of top and bottom papers. After that, a light metal pressure plate with four holes is placed on the upper paper honeycomb sandwich structure and fixed on the vibration table through four rigid threaded rods and several nuts, as shown in Figure 3. Two acceleration sensors are fixed on one side of the vibration table and at the center of the mass block. What is more, the maximal vibration transmissibility of paper honeycomb sandwich structure is the maximal ratio of the response acceleration on the mass block to the excitation acceleration on the vibration table. In sine frequency sweep experiment, the 
Table 1. Characteristics of experimental samples.

\begin{tabular}{|c|c|c|c|c|c|c|c|}
\hline Samples & $\begin{array}{l}\text { Grammage } \\
\text { of liner } \\
\text { paper } \\
\left(\mathrm{g} / \mathrm{m}^{2}\right) \\
\end{array}$ & $\begin{array}{l}\text { Grammage } \\
\text { of core } \\
\text { paper } \\
\left(\mathrm{g} / \mathrm{m}^{2}\right) \\
\end{array}$ & $\begin{array}{l}\text { Thickness } \\
\text { of liner } \\
(\mathrm{mm})\end{array}$ & $\begin{array}{l}\text { Cell wall } \\
\text { thickness } \\
(\mathrm{mm})\end{array}$ & $\begin{array}{l}\text { Cell } \\
\text { length of } \\
\text { honeycomb } \\
(\mathrm{mm})\end{array}$ & $\begin{array}{l}\text { Thickness of } \\
\text { sandwich } \\
\text { structure } \\
(\mathrm{mm})\end{array}$ & $\begin{array}{l}\text { Moisture } \\
\text { content } \\
(\%)\end{array}$ \\
\hline K230/PA110-l6-T20- $m_{1}$ & 230 & 110 & 0.28 & 0.17 & 6 & 20 & 6.23 \\
\hline $\mathrm{K} 230 / \mathrm{PA} 110-l 6-\mathrm{T} 20-m_{2}$ & 230 & 110 & 0.28 & 0.17 & 6 & 20 & 6.76 \\
\hline $\mathrm{K} 230 / \mathrm{PA} 110-l 6-\mathrm{T} 20-m_{3}$ & 230 & 110 & 0.28 & 0.17 & 6 & 20 & 7.05 \\
\hline $\mathrm{K} 230 / \mathrm{PA} 110-l 6-\mathrm{T} 20-m_{4}$ & 230 & 110 & 0.28 & 0.17 & 6 & 20 & 7.51 \\
\hline $\mathrm{K} 230 / \mathrm{PA} 110-l 6-\mathrm{T} 20-m_{5}$ & 230 & 110 & 0.28 & 0.17 & 6 & 20 & 8.20 \\
\hline $\mathrm{K} 230 / \mathrm{PA} 110-18-\mathrm{T} 20-m_{1}$ & 230 & 110 & 0.28 & 0.17 & 8 & 20 & 6.23 \\
\hline $\mathrm{K} 230 / \mathrm{PA} 110-18-\mathrm{T} 20-m_{2}$ & 230 & 110 & 0.28 & 0.17 & 8 & 20 & 6.76 \\
\hline $\mathrm{K} 230 / \mathrm{PA} 110-18-\mathrm{T} 20-m_{3}$ & 230 & 110 & 0.28 & 0.17 & 8 & 20 & 7.05 \\
\hline $\mathrm{K} 230 / \mathrm{PA} 110-18-\mathrm{T} 20-m_{4}$ & 230 & 110 & 0.28 & 0.17 & 8 & 20 & 7.51 \\
\hline $\mathrm{K} 230 / \mathrm{PA} 110-l 8-\mathrm{T} 20-m_{5}$ & 230 & 110 & 0.28 & 0.17 & 8 & 20 & 8.20 \\
\hline K230/PA110-l10-T20- $m_{1}$ & 230 & 110 & 0.28 & 0.17 & 10 & 20 & 6.23 \\
\hline $\mathrm{K} 230 / \mathrm{PA} 110-l 10-\mathrm{T} 20-m_{2}$ & 230 & 110 & 0.28 & 0.17 & 10 & 20 & 6.76 \\
\hline $\mathrm{K} 230 / \mathrm{PA} 110-l 10-\mathrm{T} 20-m_{3}$ & 230 & 110 & 0.28 & 0.17 & 10 & 20 & 7.05 \\
\hline K230/PA110-l10-T20- $m_{4}$ & 230 & 110 & 0.28 & 0.17 & 10 & 20 & 7.51 \\
\hline $\mathrm{K} 230 / \mathrm{PA} 110-l 10-\mathrm{T} 20-m_{5}$ & 230 & 110 & 0.28 & 0.17 & 10 & 20 & 8.20 \\
\hline K230/PA110- $l 10-\mathrm{T} 30-m_{1}$ & 230 & 110 & 0.28 & 0.17 & 10 & 30 & 6.23 \\
\hline $\mathrm{K} 230 / \mathrm{PA} 110-l 10-\mathrm{T} 30-m_{2}$ & 230 & 110 & 0.28 & 0.17 & 10 & 30 & 6.76 \\
\hline K230/PA110- $l 10-\mathrm{T} 30-m_{3}$ & 230 & 110 & 0.28 & 0.17 & 10 & 30 & 7.05 \\
\hline K230/PA110- $l 10-\mathrm{T} 30-m_{4}$ & 230 & 110 & 0.28 & 0.17 & 10 & 30 & 7.51 \\
\hline K230/PA110- $l 10-\mathrm{T} 30-m_{5}$ & 230 & 110 & 0.28 & 0.17 & 10 & 30 & 8.20 \\
\hline $\mathrm{K} 230 / \mathrm{PA} 110-l 10-\mathrm{T} 40-m_{1}$ & 230 & 110 & 0.28 & 0.17 & 10 & 40 & 6.23 \\
\hline K230/PA110- $l 10-\mathrm{T} 40-m_{2}$ & 230 & 110 & 0.28 & 0.17 & 10 & 40 & 6.76 \\
\hline $\mathrm{K} 230 / \mathrm{PA} 110-l 10-\mathrm{T} 40-m_{3}$ & 230 & 110 & 0.28 & 0.17 & 10 & 40 & 7.05 \\
\hline $\mathrm{K} 230 / \mathrm{PA} 110-l 10-\mathrm{T} 40-m_{4}$ & 230 & 110 & 0.28 & 0.17 & 10 & 40 & 7.51 \\
\hline $\mathrm{K} 230 / \mathrm{PA} 110-l 10-\mathrm{T} 40-m_{5}$ & 230 & 110 & 0.28 & 0.17 & 10 & 40 & 8.20 \\
\hline K230/PA140-l10-T20- $m_{1}$ & 230 & 140 & 0.28 & 0.22 & 10 & 20 & 6.76 \\
\hline $\mathrm{K} 230 / \mathrm{PA} 140-l 10-\mathrm{T} 20-m_{2}$ & 230 & 140 & 0.28 & 0.22 & 10 & 20 & 7.33 \\
\hline $\mathrm{K} 230 / \mathrm{PA} 140-l 10-\mathrm{T} 20-m_{3}$ & 230 & 140 & 0.28 & 0.22 & 10 & 20 & 7.73 \\
\hline $\mathrm{K} 230 / \mathrm{PA} 140-l 10-\mathrm{T} 20-m_{4}$ & 230 & 140 & 0.28 & 0.22 & 10 & 20 & 8.05 \\
\hline $\mathrm{K} 230 / \mathrm{PA} 140-l 10-\mathrm{T} 20-m_{5}$ & 230 & 140 & 0.28 & 0.22 & 10 & 20 & 8.77 \\
\hline K230/PA140-l10-T30- $m_{1}$ & 230 & 140 & 0.28 & 0.22 & 10 & 30 & 6.76 \\
\hline $\mathrm{K} 230 / \mathrm{PA} 140-l 10-\mathrm{T} 30-m_{2}$ & 230 & 140 & 0.28 & 0.22 & 10 & 30 & 7.33 \\
\hline $\mathrm{K} 230 / \mathrm{PA} 140-l 10-\mathrm{T} 30-m_{3}$ & 230 & 140 & 0.28 & 0.22 & 10 & 30 & 7.73 \\
\hline K230/PA140-l10-T30- $m_{4}$ & 230 & 140 & 0.28 & 0.22 & 10 & 30 & 8.05 \\
\hline $\mathrm{K} 230 / \mathrm{PA} 140-l 10-\mathrm{T} 30-m_{5}$ & 230 & 140 & 0.28 & 0.22 & 10 & 30 & 8.77 \\
\hline $\mathrm{K} 230 / \mathrm{PA} 140-l 10-\mathrm{T} 40-m_{1}$ & 230 & 140 & 0.28 & 0.22 & 10 & 40 & 6.76 \\
\hline K230/PA140- $l 10-\mathrm{T} 40-m_{2}$ & 230 & 140 & 0.28 & 0.22 & 10 & 40 & 7.33 \\
\hline $\mathrm{K} 230 / \mathrm{PA} 140-l 10-\mathrm{T} 40-m_{3}$ & 230 & 140 & 0.28 & 0.22 & 10 & 40 & 7.73 \\
\hline K230/PA140-l10-T40- $m_{4}$ & 230 & 140 & 0.28 & 0.22 & 10 & 40 & 8.05 \\
\hline $\mathrm{K} 230 / \mathrm{PA} 140-l 10-\mathrm{T} 40-m_{5}$ & 230 & 140 & 0.28 & 0.22 & 10 & 40 & 8.77 \\
\hline
\end{tabular}

frequency range is $5-500 \mathrm{~Hz}$, frequency sweep rate is 1 Oct/ min, acceleration is $0.5 \mathrm{~g}$, and the weight of the mass block is chosen to be $16 \mathrm{~kg}$.

In Table 1, K230/PA110-l10-T20- $m_{1}$ indicates a paper honeycomb sandwich structure with liner paper grammage of $230 \mathrm{~g} / \mathrm{m}^{2}$, core paper grammage of $110 \mathrm{~g} / \mathrm{m}^{2}$, cell length of $10 \mathrm{~mm}$, and thickness of $20 \mathrm{~mm}$ under $m_{1}$ condition. The value of $m_{1}$ is the moisture content of core base paper with grammage of $110 \mathrm{~g} / \mathrm{m}^{2}$ under $23^{\circ} \mathrm{C}$ and $\mathrm{RH} 50 \%$, which is measured by moisture teller (SFY20A; Shenzhen post 


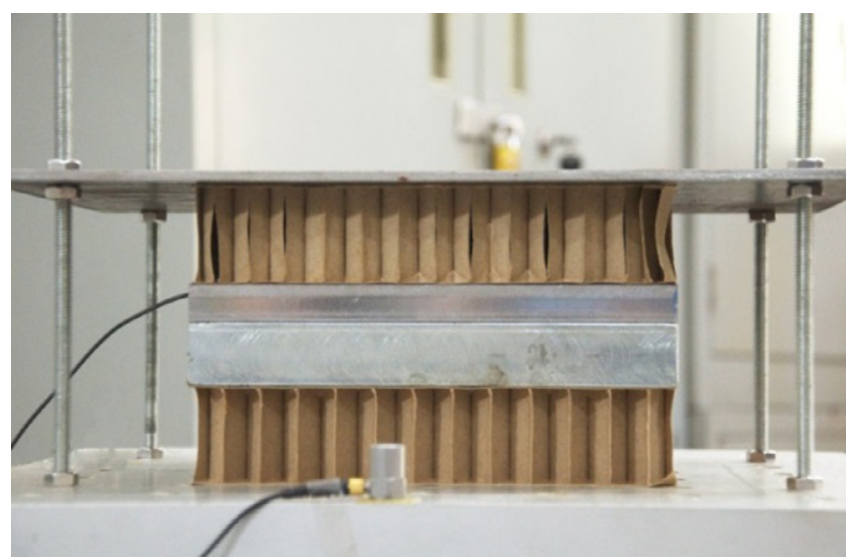

Fig. 3. The mount and fixture of test specimen.

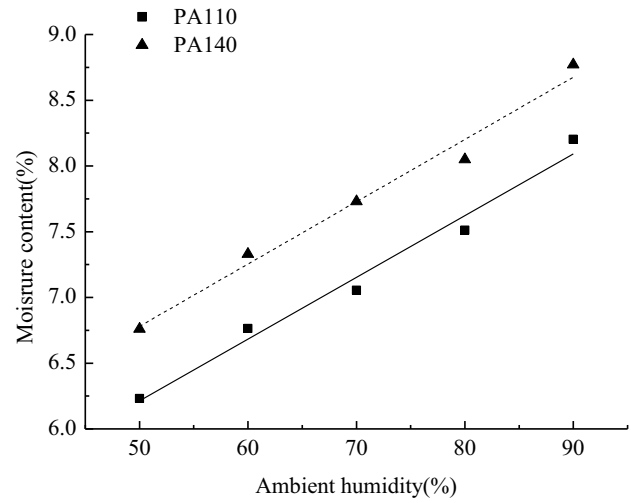

Fig. 4. Variation of moisture content for core base paper under different ambient humidity.

Wang Electronic Technology Co., Ltd.), drying for 5 min at $105^{\circ} \mathrm{C}$. The main force part of paper honeycomb sandwich structure is honeycomb core, so in this research, the moisture content of core base paper is taken as an index to analyze the effect of different humidity on the maximal vibration transmissibility of paper honeycomb sandwich structure. Figure 4 shows a close linear relationship between moisture content and humidity.

\section{Experimental results and analysis}

\subsection{Rule of maximal vibration transmissibility}

As shown in Figure 5, the vibration transmissibilityfrequency curve can be divided into three parts: (I) lowfrequency zone, (II) resonance amplification zone, and (III) vibration isolation zone. The vibration transmissibility in low-frequency zone is kept at about $1 \mathrm{~g} / \mathrm{g}$, which is of little significance for antivibration analysis. In the resonance zone, there is an obvious peak point, in which the $\mathrm{X}$-axis coordinate point is the main resonance frequency and the Y-axis coordinate point is the maximal vibration transmissibility. When excitation frequency is close to resonance frequency point, the system will resonate and the product will suffer the most vibration damage. And in isolation

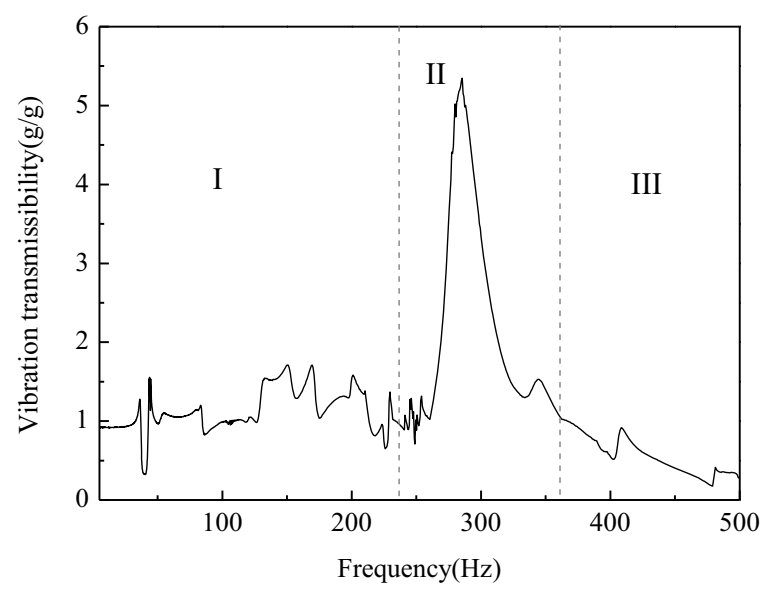

Fig. 5. Typical vibration transmissibility-frequency curve of paper honeycomb sandwich structure.

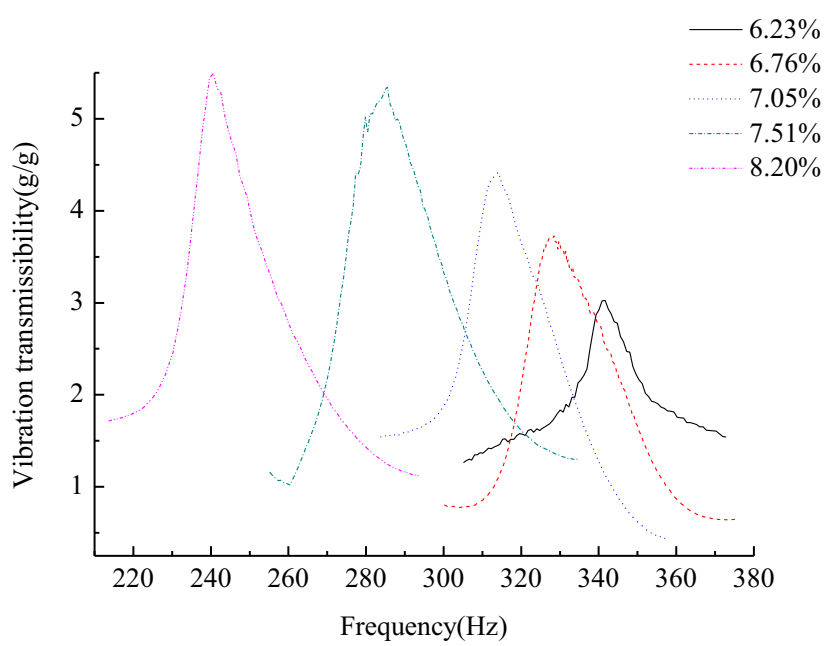

Fig. 6. Influence of moisture content on vibration transmissibility-frequency curves of paper honeycomb sandwich structures.

zone, the vibration transmissibility unceasingly attenuates until it approaches zero.

The change of ambient humidity affects the moisture content of base paper and then affects the maximal vibration transmissibility and corresponding frequency of paper honeycomb sandwich structure. The influence of moisture content on vibration transmissibility of paper honeycomb sandwich structure is shown in Figure 6. In order to highlight the characteristics of the maximum peak of the curve, only the results of the vibration transmissibility-frequency curves in the resonance zone are shown. It can be seen that the vibration transmissibility-frequency curve of paper honeycomb sandwich structure moves to the upper left with the increase of moisture content, that is to say, the maximal vibration transmissibility increases gradually with the increase of moisture content.

From the experimental scatter points of maximal vibration transmissibility in Figure 7, it can obviously be found that the greater the moisture content is, the greater the maximal vibration transmissibility is. As moisture 
content increases, paper fibers arises moisture expansion and the free volume of fiber increases, the methoxy groups in the gaps of paper fibers are easier to combine with hydrogen bonds and form more carbohydrates, which reduces the viscosity of the structure [4] and increases the maximal vibration transmissibility. We know from previous studies that in high-humidity environment, the elastic modulus [1], tensile strength [2], and compression strength $[11,12]$ of paper honeycomb sandwich structures will be reduced, and the experimental results of this paper show that the vibration absorption capacity will also be decreased. Therefore, it is necessary to optimize the papermaking process reasonably and increase the moisture resistance of paper.

It is also seen from Figure 7 that the size of the honeycomb structure also affects the maximal vibration transmissibility. Under the same moisture content, the maximal vibration transmissibility of paper honeycomb sandwich structure increases with the increase of cell length of honeycomb. Keeping the honeycomb length constant, the maximal vibration transmissibility will further increase by increasing the thickness of sandwich structure. Because the small cell length of honeycomb has more damping and energy absorbing units, the vibration transmissibility is small. What is more, the thickness of the sandwich structure is small, the movement volume of air in unit

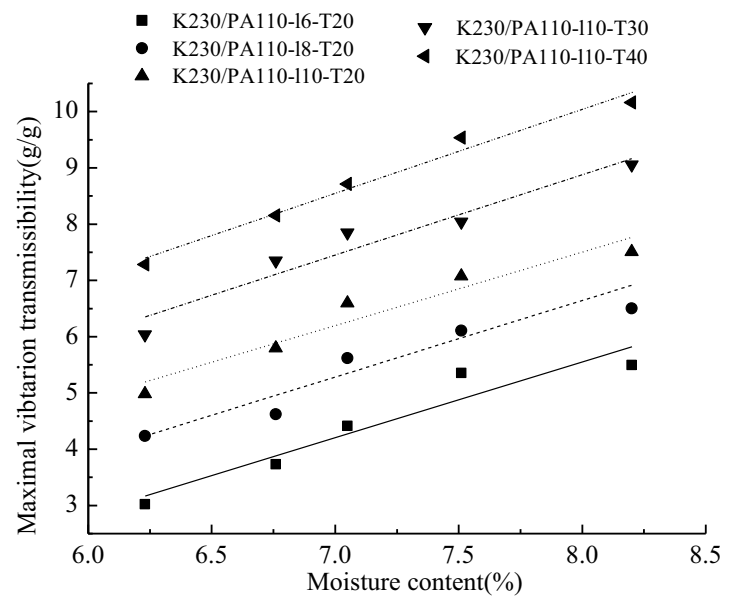

Fig. 7. Effect of moisture content on the maximal vibration transmissibility of paper honeycomb sandwich structures with different sizes. cell will be small, the collision between air molecules will be more intense, and more vibration energy will be converted to heat and dissipation. Thus, comparatively speaking, the paper honeycomb sandwich structure with small cell size and small thickness has better vibration isolation performance.

\subsection{Maximal vibration transmissibility evaluation equation}

It can be seen from Figure 7 that the maximal vibration transmissibility changes close to linear with the change of honeycomb structure size and the moisture content. According to the maximal vibration transmissibility experimental values of five kinds of paper honeycomb sandwich structures under the standard temperature and humidity condition $\left(23{ }^{\circ} \mathrm{C}, \mathrm{RH} 50 \%\right)$, the maximal vibration transmissibility evaluation equation is obtained:

$$
T r_{m}=0.48 l+0.11 T-1.97
$$

where $\operatorname{Tr}_{m}$ is the maximal vibration transmissibility, $l$ is the cell length of honeycomb, and $T$ is the thickness of sandwich structure. The $R^{2}$ acquired by fitting is 0.995 , so the fitting equation is reasonable.

If we want to further obtain the vibration transmissibility of paper honeycomb sandwich structures with different materials under various humidity, we only need to add the moisture content parameter and material parameter in equation (1). But the moisture content varies in different materials. In order to eliminate the difference of water absorption capacity of different materials, the moisture content values in different humidity were standardized. The specific approach is used to divide the moisture content of a material under different humidity by the moisture content of the materials in the standard environment. In this way, the maximal vibration transmissibility equation related to the standardized moisture content factor can easily be obtained; its form is as follows:

$$
T r_{m}=C\left(a_{1} \% m+a_{2} l+a_{3} T+a_{4}\right)
$$

where $C$ is a coefficient related to material, $\% m$ is the standardized moisture content, coefficients of $a_{1}, a_{2}, a_{3}$, and $a_{4}$ need to be determined by experimental data. The fitting results of different samples are listed in Table 2 .

Table 2. Fitting results of different samples.

\begin{tabular}{llllr}
\hline Samples & $a_{1}$ & $a_{2}$ & $a_{3}$ & $a_{4}$ \\
\hline K230/PA110-l6-T20 & 8.39 & 0.48 & 0.11 & -10.31 \\
K230/PA110-l8-T20 & 7.69 & 0.48 & 0.11 & -9.45 \\
K230/PA110-l10-T20 & 8.14 & 0.48 & 0.11 & -9.95 \\
K230/PA110-l10-T30 & 8.90 & 0.48 & 0.11 & -10.65 \\
K230/PA110-l10-T40 & 9.31 & 0.48 & 0.11 & -11.12 \\
Average value & 8.49 & 0.48 & 0.11 & -10.30 \\
\hline
\end{tabular}


Table 3. Comparison of maximal vibration transmissibility experimental values $\left(T r_{m}^{\prime}\right)$ and fitting values $\left(\operatorname{Tr}_{m}^{\prime \prime}\right)$.

\begin{tabular}{lllllll}
\hline Samples & $\% m$ & $l(\mathrm{~mm})$ & $T(\mathrm{~mm})$ & $T r_{m}^{\prime}(\mathrm{g} / \mathrm{g})$ & $T r_{m}^{\prime \prime}(\mathrm{g} / \mathrm{g})$ & $\Delta E(\%)$ \\
\hline K230/PA110-l6-T20- $m_{1}$ & 1.00 & 6 & 20 & 3.02 & 3.27 & 8.23 \\
K230/PA110-l6-T20- $m_{2}$ & 1.09 & 6 & 20 & 3.73 & 3.99 & 7.03 \\
K230/PA110-l6-T20- $m_{3}$ & 1.13 & 6 & 20 & 4.41 & 4.39 & 0.56 \\
K230/PA110-l6-T20- $m_{4}$ & 1.21 & 6 & 20 & 5.35 & 5.02 & 6.31 \\
K230/PA110-l6-T20- $m_{5}$ & 1.32 & 6 & 20 & 5.50 & 5.96 & 8.39 \\
K230/PA110-l8-T20- $m_{1}$ & 1.00 & 8 & 20 & 4.24 & 4.23 & 0.09 \\
K230/PA110-l8-T20- $m_{2}$ & 1.09 & 8 & 20 & 4.62 & 4.95 & 7.18 \\
K230/PA110-l8-T20- $m_{3}$ & 1.13 & 8 & 20 & 5.62 & 5.35 & 4.79 \\
K230/PA110-l8-T20- $m_{4}$ & 1.21 & 8 & 20 & 6.11 & 5.98 & 2.17 \\
K230/PA110-l8-T20- $m_{5}$ & 1.32 & 8 & 20 & 6.50 & 6.92 & 6.35 \\
K230/PA110-l10-T20- $m_{1}$ & 1.00 & 10 & 20 & 4.98 & 5.19 & 4.24 \\
K230/PA110-l10-T20- $m_{2}$ & 1.09 & 10 & 20 & 5.80 & 5.91 & 2.02 \\
K230/PA110-l10-T20- $m_{3}$ & 1.13 & 10 & 20 & 6.60 & 6.31 & 4.38 \\
K230/PA110-l10-T20- $m_{4}$ & 1.21 & 10 & 20 & 7.07 & 6.94 & 1.96 \\
K230/PA110-l10-T20- $m_{5}$ & 1.32 & 10 & 20 & 7.51 & 7.88 & 4.88 \\
K230/PA110- l10-T30- $m_{1}$ & 1.00 & 10 & 30 & 6.03 & 6.29 & 4.26 \\
K230/PA110-l10-T30- $m_{2}$ & 1.09 & 10 & 30 & 7.38 & 7.01 & 4.54 \\
K230/PA110-l10-T30- $m_{3}$ & 1.13 & 10 & 30 & 7.85 & 7.41 & 5.57 \\
K230/PA110-l10-T30- $m_{4}$ & 1.21 & 10 & 30 & 8.04 & 8.04 & 0.04 \\
K230/PA110-l10-T30- $m_{5}$ & 1.32 & 10 & 30 & 9.06 & 8.98 & 0.88 \\
K230/PA110-l10-T40- $m_{1}$ & 1.00 & 10 & 40 & 7.28 & 7.39 & 1.50 \\
K230/PA110-l10-T40- $m_{2}$ & 1.09 & 10 & 40 & 8.15 & 8.11 & 0.50 \\
K230/PA110- l10-T40- $m_{3}$ & 1.13 & 10 & 40 & 8.71 & 8.51 & 2.35 \\
K230/PA110-l10-T40- $m_{4}$ & 1.21 & 10 & 40 & 9.53 & 9.14 & 4.18 \\
K230/PA110-l10-T40- $m_{5}$ & 1.32 & 10 & 40 & 10.16 & 10.08 & 0.83 \\
\hline
\end{tabular}

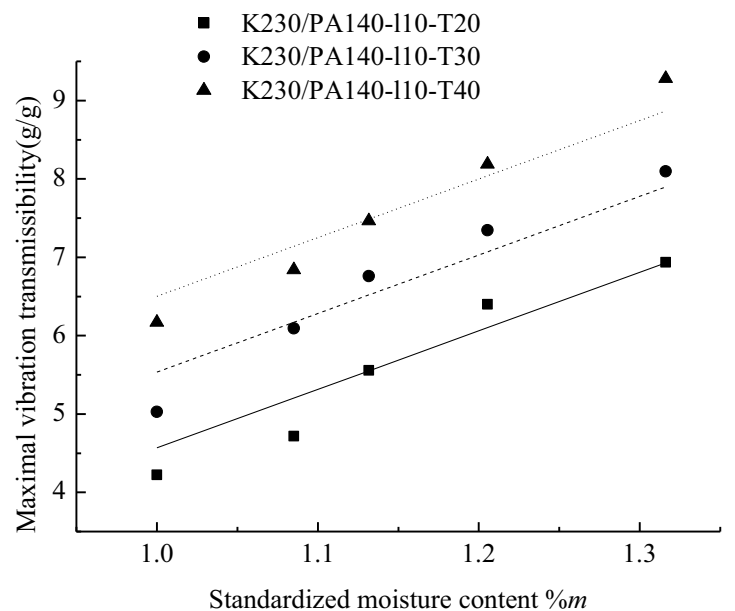

Fig. 8. Maximal vibration transmissibility rule of verifying samples.

So, the evaluation equation for maximal vibration transmissibility of paper honeycomb sandwich structure is as follows:

$$
\operatorname{Tr}_{m}=C(8.49 \% m+0.48 l+0.11 T-10.30)
$$

Here, the material coefficient is taken as $1 . R^{2}$ is 0.981 , the experimental values in Figure 4 are close to fitting curves, and the error in Table 3 is less than $8.39 \%$, indicating that the evaluation equation is reasonable.

\subsection{Evaluation equation verification}

To test the applicability of the evaluation equation, equation (3) was verified by paper honeycomb sandwich structures with core paper grammage of $140 \mathrm{~g} / \mathrm{m}^{2}$, cell length of $10 \mathrm{~mm}$, and thickness of $20 \mathrm{~mm}, 30 \mathrm{~mm}$, and $40 \mathrm{~mm}$, respectively.

The $C$ value in equation (3) obtained from the verification sample is 0.88 . The result of $R^{2}$ is 0.973 , very close to 1 , and the fitting curves in Figure 8 are close to the experimental values, so equation (3) can be used to predict the maximal vibration transmissibility of paper honeycomb sandwich structures with other grammage.

\section{Conclusions}

Based on sine sweep frequency experiments, the vibration transmission characteristics of paper honeycomb sandwich structures with different humidity were analyzed, 
and the evaluation equations of maximal vibration transmissibility for paper honeycomb sandwich structures with moisture content and honeycomb structure size were obtained. The conclusions are as follows:

1. With the increase of moisture content, the vibration transmissibility-frequency curve moves to the upper left, and the maximal vibration transmissibility increases with the increase of moisture content, cell length of honeycomb, and thickness of sandwich structure.

2. Equation (3) could reasonably predict the maximal vibration transmissibility value of paper honeycomb sandwich structure under different humidity environments and is helpful to optimize the antivibration structure and reduce the packaging cost.

Acknowledgements. This work was supported by the financial support from the National Natural Science Foundation of China (No: 51675349).

\section{References}

[1] S. Zauscher, D.F. Caulfield, A.H. Nissan, The influence of water on the elastic modulus of paper, Part I: extension of the H-bond theory, Tappi J. 79 (1996) 178-182

[2] L. Salmén, E. Back, Effects of temperature and moisture on the tensile properties of packaging paper, Pap. Puu. 67 (1985) 477-482

[3] G.N. Christensen, W.W. Barkas, Physical properties of paper pulps: elastic properties of wet mats of papermaking fibres, Nature 171 (1953) 165-166

[4] D. Caulfield, Effect of moisture and temperature on the mechanical properties of paper, Syracuse University, New York, 1990, pp. 50-62

[5] H.W. Haslach Jr., The moisture and rate-dependent mechanical properties of paper: a review, Mech. Time Depend. Mater. 4 (2000) 169-210
[6] J. Kubát, B. Lindbergson, Damping transients in polymers during sorption and desorption, J. Appl. Polym. Sci. 9 (1965) 2651-2654

[7] Y.-P. E, Z.W. Wang, Plateau stress of paper honeycomb as response to various relative humidities, Packag. Technol. Sci. 23 (2010) 203-216

[8] Z.W. Wang, Y.-P. E, Mathematical modelling of energy absorption property for paper honeycomb in various ambient humidities, Mater. Des. 31 (2010) 4321-4328

[9] D.M. Wang, H.X. Gong, Z.Y. Bai, Effect investigation of relative humidity and temperature on multi-layer corrugated sandwich structures, J. Sandw. Struct. Mater. 15 (2013) 156-167

[10] Z.W. Wang, Y.-P. E, Energy absorption properties of multilayered corrugated paperboard in various ambient humidities, Mater. Des. 32 (2011) 3476-3485

[11] Y.Z. Xiao, Z.Z. Shao, Effect of temperature on the static compression of molded pulp productions, in: 5th International Conference on Civil Engineering and Transportation, 2015, pp. $1786-1791$

[12] N. Navaranjan, A. Dickson, J. Paltakari, I. Kai, Humidity effect on compressive deformation and failure of recycled and virgin layered corrugated paperboard structures, Compos. Part B 45 (2013) 965-971

[13] J. Park, G. Kim, H. Kim, J. Park, G. Kim, H. Kim, S. Kwon, M. Mitusoka, E. Inoue, T. Okayasu, Characteristics of vibration transmissibility for corrugated paperboard, J. Fac. Agr. Kyushu Univ. 56 (2011) 327-333

[14] Y.F. Guo, J.H. Zhang, Shock absorbing characteristics and vibration transmissibility of honeycomb paperboard, Shock Vib. 11 (2004) 521-531

[15] B.Z. Wang, L.J. Cao, Different thickness of honeycomb paperboard vibration frequency of testing and simulation, Adv. Mater. Res. 328-330 (2011) 1421-1424

[16] D.P. Zhu, S.S. Zhou, R.C. He, Estimation of dynamic properties of honeycomb paperboard and parameters identification, IJET 3 (2011) 485-490

[17] L. Zhang, Honeycomb paper pallet stacking experimental analysis of dynamic characteristics, China Mod. Edu. Equip. 13 (2010) 68-71

Cite this article as: D.-M. Wang, R. Yang, Investigation of vibration transmissibility for paper honeycomb sandwich structures with various moisture contents, Mechanics \& Industry 20, 108 (2019) 